\title{
Declínio da prevalência do HTLV-1/2 em doadores de sangue do Hemocentro Regional da Cidade de Uberaba, Estado de Minas Gerais, 1995 a 2008
}

\author{
Decline in the prevalence of HTLV-1/2 among blood donors at the Regional Blood Center \\ of the City of Uberaba, State of Minas Gerais, from 1995 to 2008
}

Guilherme Manso de Lima ${ }^{1,2}$, José Martins Juliano Eustáquio ${ }^{2}$, Raquel Alves Martinss ${ }^{3}$,Juliana Alves Josahkian ${ }^{2}$,
Gilberto de Araújo Pereira $^{4}$, Helio Moraes-Souza ${ }^{5,6}$ e Paulo Roberto Juliano Martins $^{5,6}$

\section{RESUMO}

Introdução: Estudo retrospectivo com o objetivo de avaliar a prevalência e fatores associados à soropositividade para o HTLV-1/2, no período de 1995 a 2008, no Hemocentro Regional de Uberaba e descrever os doadores soropositivos quanto ao gênero, idade, estado civil, cor de pele e procedência. Métodos: Foram realizados análise estatística descritiva, testes quiquadrado e odds ratio para comparação de proporções e gráfico de dispersão com coeficiente de correlação linear. Resultados: Dentre $\mathrm{x}$ doadores testados, foi encontrada a prevalência de sorologia positiva para o HTLV de $0,02 \%$ e indeterminada de $0,09 \%$. Houve uma redução significativa da sorologia positiva para HTLV, no período de 2002 a 2008, em comparação ao período de 1995 a 2001. Dentre os soropositivos, observou predomínio significante no gênero feminino. Conclusões: Imputamos a queda gradativa de soropositividade no período à exclusão permanente dos doadores de repetição soropositivos e ao aprimoramento dos métodos de triagem clínica e dos testes sorológicos ao longo dos anos com reflexos positivos na segurança transfusional.

Palavras-chaves: Prevalência. HTLV-1/2. Doadores de sangue. Western Blot.

\begin{abstract}
Introduction: A retrospective study was conducted in order to assess the prevalence and factors associated with seropositivity for HTLV-1/2 between 1995 and 2008 in Uberaba Regional Blood Center, and to describe the seropositive blood donors in relation to gender, age, marital status, skin color and origin. Methods: Descriptive statistical analysis, chi-square tests and odds ratios were produced to compare proportions, along with scatter charts with linear correlation coefficients. Results: Among the donors tested, the prevalence of seropositivity for HTLV was found to be $0.02 \%$, with indeterminate results in $0.09 \%$. There was a significant reduction in seropositivity for HTLV between 2002 and 2008, compared with the period from 1995 to 2001. Among the seropositive individuals, females were significantly predominant. Conclusions: The gradual decrease in seropositivity over this period was attributed to the permanent exclusion of seropositive repeat donors and improvement in the clinical screening methods and serological tests over the years, with a positive impact on transfusion safety.
\end{abstract}

Key-words: Prevalence. HTLV-1/2. Blood donors. Western Blot.

1. Bolsista de Iniciação Científica, Fundação de Amparo à Pesquisa do Estado de Minas Gerais, Belo Horizonte, MG. 2. Curso de Graduação em Medicina, Universidade Federal do Triângulo Mineiro, Uberaba, MG. 3. Curso de Graduação em Medicina, Universidade de Uberaba, Uberaba, MG. 4. Disciplina de Bioestatística, Universidade Federal do Triângulo Mineiro, Uberaba, MG. 5. Disciplina de Hematologia e Hemoterapia, Universidade Federal do Triângulo Mineiro, Uberaba, MG. 6. Hemocentro Regional de Uberaba, Uberaba, MG.

Endereço para correspondência: Dr. Paulo Roberto Juliano Martins. HRU. Av. Getúlio Guarita 250/ $4^{\circ}$ andar, Bairro Abadia, 38025-440 Uberaba, MG.

Tel: 5534 3312-5077

e-mail: ura.coordenacao@hemominas.mg.gov.br

Recebido para publicação em 27/01/2010

Aceito em 12/05/2010

\section{INTRODUÇÃO}

O vírus linfotrópico de células Thumana (HTLV) é um vírus que pertence à família Retroviridae. Embora sejam antigas as infecções humanas causadas por esse vírus, o isolamento do HTLV-1 ocorreu em 1980 de um paciente com linfoma cutâneo de células $\mathrm{T}^{1}$. Aproximadamente, $95 \%$ dos portadores do HTLV-1 permanecem assintomáticos ${ }^{2}$ e uma minoria desenvolve doenças como: linfoma/leucemia de células T do adulto (ATL/L), paraparesia espástica tropical, também, conhecida como mielopatia associada ao HTLV (HAM/TSP) e uveítes ${ }^{3-11}$. Um segundo vírus, o HTLV-2, foi identificado em 1982, isolado de um paciente com leucemia de células pilosas. Porém, não há associação comprovada deste com qualquer doença ${ }^{12}$.

Acredita-se que a infecção tenha originado no continente africano e, nos séculos XVI e XVII, se espalhou para as ilhas do Caribe, pelo tráfico de escravos e para o Japão, pelos navios portugueses ${ }^{1}$. O HTLV-I tem distribuição universal, já o tipo dois é predominante no hemisfério ocidental ${ }^{1}$. Estimase entre 15 e 20 milhões de pessoas contaminadas pelo HTLV no mundo. O Brasil é considerado o país com o maior número absoluto de portadores dessa retrovirose ${ }^{8}$, já o Japão foi o primeiro a ser identificado como endêmico ${ }^{1,4}$. Há relatos de que a prevalência aumente com a idade e seja maior no sexo feminino ${ }^{1,13}$. No Brasil, os estudos iniciaram em $1986^{1,4,14}$; ainda assim, há poucos levantamentos de soroprevalência na população geral ${ }^{1}$.

A transmissão ocorre por via sexual, aleitamento materno prolongado, transplacentária e exposição ao sangue $^{15}$. Devido ao risco de transmissão parenteral, em novembro de 1993, o governo brasileiro tornou obrigatório o teste de triagem nos bancos de sangue $^{16}$, seguindo os exemplos de países como Japão em 1986 e Estados Unidos da América em 1988 4,17. A Fundação Centro de Hematologia e Hemoterapia de 
Minas Gerais (Hemominas), antecipando a exigência legal, incluiu o teste de triagem e o confirmatório em março de $1993^{15}$. O teste sorológico de triagem mais utilizado é o enzyme linked immunosorbent assay (ELISA), que apesar da sua alta sensibilidade, possui baixo valor preditivo positivo, apresentando frequentes reações falso-positivas. Assim, é necessário o diagnóstico confirmatório pelas técnicas de Western Blot (WB) ou imunofluorescência indireta (IFI) $)^{2,18}$.

Este estudo tem como objetivos verificar, no Hemocentro Regional de Uberaba (HRU), pertencente à Fundação Hemominas, a prevalência de inaptidão sorológica para o $\mathrm{HTLV}-1 / 2$, a tendência da soropositividade no período estudado e, dentre as soropositivos, o perfil dos doadores.

\section{MÉTODOS}

Estudo retrospectivo descritivo dos testes sorológicos antiHTLV-1/2 nas doações de sangue do HRU (Fundação Hemominas) de $1^{\circ}$ de janeiro de 1995 a 31 de dezembro de 2008. Montou-se um banco de dados de indivíduos que apresentavam sorologia positiva e indeterminada para os testes ELISA e Western Blot. Os dados pessoais foram identificados pelo número de registro no Hemocentro, preservando a confidencialidade.

Para o cálculo da ocorrência de doações com sorologia positiva, foram descritos os valores absolutos e relativos. Na caracterização epidemiológica, foram considerados aqueles com Western Blot positivo e avaliou os seguintes parâmetros: gênero (masculino e feminino), faixa etária ( 18 a 29 anos e igual ou maior de 30 anos), estado civil (casado, solteiro e outro), cor da pele (branca e não branca) e procedência (Uberaba e não Uberaba). Estes dados foram ainda analisados em dois períodos distintos, 1995 a 2001 e 2002 a 2008. Para estudar as características de interesse, foi realizado o teste qui-quadrado e calculado o odds ratio (razão de chances) com intervalo de confiança de $95 \%{ }^{19}$. O estudo de tendência nos diferentes anos foi realizado através do gráfico de dispersão e do coeficiente de correlação linear (r), com nível de significância de $5 \%{ }^{19}$.

\section{Ética}

O projeto foi aprovado pelo comitê de ética e pesquisa da Fundação Hemominas com o parecer número 162 (05/03/2007).

\section{RESULTADOS}

Dos 147.489 doadores, $461(0,3 \%)$ apresentaram $1^{\text {a }}$ amostra reagente pelo ELISA, dos quais 379 apresentaram-se para coleta de $2^{\circ}$ amostra, sendo que 163 (43\%) tornaram-se aptos à doação. O Western Blot nos outros 216 doadores resultou em 36 reações positivas, portanto uma soropositividade de $0,02 \%, 140(0,09 \%)$ indeterminadas e $40(0,03 \%)$ negativas (Tabela 1). Das 36 sorologias positivas para o HTLV, 33 eram doadores em uma primeira doação (doadores novos) e os outros três eram doadores de retorno, cuja doação precedente fora negativa.

O comportamento sorológico ao longo do período evidenciou, pelo ELISA, maior incidência de 1995 a 1998, com pico em 1997, quando $1,05 \%$ das amostras apresentaram-se reagentes. Ocorreu queda gradativa nos anos subsequentes e se manteve relativamente estável a partir de 2002 (Tabela 2).

Quanto ao WB, ao longo do período estudado, foi observada moderada tendência decrescente da soropositividade $(r=-0,5)$, com a ocorrência de 5,60 para 10 mil doadores em 1995 e
TABELA 1 - Perfil sorológico pelos testes ELISA e Western Blot dos 147.489 doadores do Hemocentro Regional de Uberaba, no período de 1.995 a 2.008.

\begin{tabular}{|c|c|c|c|c|c|}
\hline Teste & Amostra & Resultado & Doadores $\left(n^{\circ}\right)$ & Amostra (\%) & Total (\%) \\
\hline \multirow[t]{3}{*}{ ELISA } & primeira & reagente & 461 & 0,3 & 0,3 \\
\hline & & não reagente & 147.028 & 99,7 & 99,7 \\
\hline & & total & 147.489 & 100,0 & 100,0 \\
\hline \multirow[t]{3}{*}{ ELISA } & segunda* & reagente & 216 & 57,0 & 0,2 \\
\hline & & não reagente & 163 & 43,0 & 0,1 \\
\hline & & total & 379 & 100,0 & 0,3 \\
\hline \multirow[t]{4}{*}{ Western Blot } & única** & reagente & 36 & 16,7 & 0,02 \\
\hline & & indeterminado & 140 & 64,8 & 0,09 \\
\hline & & não reagente & 40 & 18,5 & 0,03 \\
\hline & & total & 216 & 100,0 & 0,2 \\
\hline
\end{tabular}

Fonte: Banco de dados do HRU/Fundação Hemominas.

* para a segunda amostra do teste ELISA compareceram somente 379 dos 461 doadores reagentes na primeira amostra; ${ }^{* *}$ para a primeira e única amostra do teste Western Blot foram considerados os 216 doadores reagentes na segunda amostra do teste ELISA

TABELA 2 - Prevalência de sorologia positiva para o vírus HTLV-I/II a partir dos testes de ELISA ( $1^{\text {a }}$ amostra) e Western Blot realizados no Hemocentro Regional de Uberaba, nos períodos de 1995 a 2001 e 2002 a 2008.

\begin{tabular}{|c|c|c|c|c|c|}
\hline \multirow[b]{2}{*}{ Periodo } & \multirow{2}{*}{$\begin{array}{c}\text { Doadores } \\
n^{\circ}\end{array}$} & \multicolumn{2}{|c|}{ ELISA $1^{\mathrm{a}}$ amostra } & \multicolumn{2}{|c|}{ Western Blot } \\
\hline & & $\mathrm{n}^{\mathrm{o}}$ & $\%$ & $\mathrm{n}^{\mathrm{o}}$ & $\%$ \\
\hline 1995 a 2000 & 71.214 & 395 & 0,6 & 25 & 0,035 \\
\hline 2002 a 2008 & 76.275 & 66 & 0,1 & 11 & 0,014 \\
\hline \multirow[t]{3}{*}{ Total } & 147.489 & 461 & 0,3 & 36 & 0,02 \\
\hline & $\chi^{2}$ & \multicolumn{2}{|c|}{$257,5(\mathrm{p}<0,0001)$} & \multicolumn{2}{|c|}{$5,6(p=0,0176)$} \\
\hline & OR (IC95\%) & \multicolumn{2}{|c|}{$6,4(4,96 ; 8,36)$} & \multicolumn{2}{|c|}{$2,4(1,2 ; 4,9)$} \\
\hline
\end{tabular}

Fonte: Banco de dados do HRU/Fundação Hemominas.

apenas 0,90 em 2008. Como no ELISA, observou-se elevada ocorrência de 1995 a 1998, com pico de 8,44 em 1998, enquanto em 2002 não foi identificado nenhum doador infectado pelo HTLV-1/2 (Tabela 2 e Figura 1).

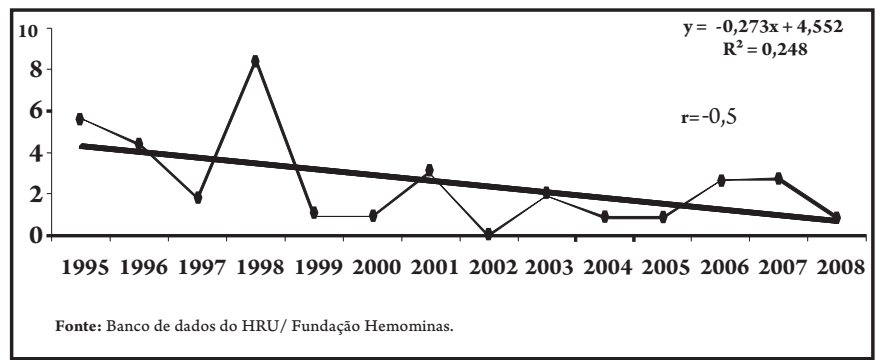

FIGURA 1 - Prevalência anual de sorologia positiva pelo Western Blot, para cada 10 mil doadores, de 1995 a 2008.

Tanto para o teste ELISA quanto para o WB, houve uma redução significativa de soro positividade para HTLV no período de 2002 a 2008 em comparação ao período de 1995 a 2001, $\left(\chi^{2}:=257,5\right.$ e $\mathrm{p}<0,0001 ; \chi^{2}=5,6$ e $\mathrm{p}=0,0176$, respectivamente). A chance de encontrar sorologia positiva para HTLV, pelo teste de ELISA, no período de 1995 a 2001, é de 4,96 a 8,36 vezes maior que a no período de 2002 a 2008 e pelo WB esta mesma chance é de 1,2 a 4,9 vezes maior (Tabela 3).

A análise do perfil epidemiológico dos doadores com teste confirmatório positivo (WB) e sua correlação com os 147.489 doadores de sangue do período, está representada na Tabela 3. Observou-se que a maioria dos doadores de sangue do HRU 
é do gênero masculino (71,8\%), idade igual ou superior a 30 anos (52\%), estado civil casado (47,5\%), cor branca $(63,5 \%)$ e procedente de Uberaba (86,5\%). Quanto aos 36 soropositivos pelo $\mathrm{WB}$, encontramos maior ocorrência em mulheres, idade igual ou superior a 30 anos, estado civil outros (não casado e não solteiro), não brancos e procedentes de Uberaba. Na Tabela 3, a diferença estatisticamente significativamente foi observada apenas com relação ao gênero $\left(\chi^{2}=7,4 ; \mathrm{p}=0,007\right)$, sendo a chance de sorologia positiva entre as mulheres de 1,3 a 4,9 vezes maior em relação aos homens $(\mathrm{OR}=2,5(1,3-4,9)$.

TABELA 3 - Perfil epidemiológico de doadores de sangue do Hemocentro Regional de Uberaba com sorologia positivas para o HTLV-I/II pelo Western Blot, quanto ao gênero, idade, estado civil, cor da pele e procedência, no período de 1995 a 2008.

\begin{tabular}{|c|c|c|c|c|c|c|}
\hline Características & № & $\%$ & I & $\begin{array}{c}P / \\
10.000 \\
\end{array}$ & $\begin{array}{c}\text { Valor-p } \\
\left(\chi^{2}\right) \\
\end{array}$ & $\begin{array}{c}\text { OR } \\
(\text { IC95\%) } \\
\end{array}$ \\
\hline \multicolumn{7}{|l|}{ Gênero } \\
\hline masculino & 105.856 & 71,8 & 18 & 1,70 & $0,007^{*}$ & $2,5(1,3-4,9)^{*}$ \\
\hline feminino & 41.633 & 28,2 & 18 & 4,32 & & \\
\hline \multicolumn{7}{|c|}{ Faixa etária (anos) } \\
\hline $18-29$ & 70.832 & 48,0 & 17 & 2,40 & 0,92 & $1,03(0,54-2,0)$ \\
\hline $30-60$ & 76.657 & 52,0 & 19 & 2,48 & & \\
\hline \multicolumn{7}{|l|}{ Estado civil } \\
\hline casado & 70.049 & 47,5 & 16 & 2,28 & 0,89 & $1,12(0,6-2,3)$ \\
\hline solteiro & 58.648 & 39,8 & 15 & 2,56 & 0,98 & $1,17(0,43-3,2)$ \\
\hline outro & 18.792 & 12,7 & 5 & 2,66 & & \\
\hline \multicolumn{7}{|l|}{ Cor da pele } \\
\hline não branca & 53.810 & 36,5 & 13 & 2,42 & 0,96 & $1,01(0,5-2,0)$ \\
\hline branca & 93.679 & 63,5 & 23 & 2,46 & & \\
\hline \multicolumn{7}{|l|}{ Procedência } \\
\hline não Uberaba & 19.899 & 13,5 & 4 & 2,01 & 0,86 & $1,25(0,44-3,53)$ \\
\hline Uberaba & 127.590 & 86,5 & 32 & 2,51 & & \\
\hline
\end{tabular}

Fonte: Banco de dados do HRU/Fundação Hemominas.

* diferença significativa; P: prevalência (valor absoluto); I/10.000: coeficiente de prevalência para 10.000 doadores; OR: odds ratio; IC95\%: intervalo de confiança de $95 \%$ para o odds ratio.

\section{DISCUSSÃO}

No período estudado, a taxa de inaptidão sorológica para HTLV, pelo teste de ELISA, foi de $0,31 \%$. Dados da ANVISA apontam, para os anos de 2005 e 2006, inaptidão de, respectivamente, 0,17\% e 0,19\% para o território nacional e $0,24 \%$ e $0,22 \%$ para a região sudeste ${ }^{20}$. Em nosso estudo para esses dois anos, encontramos uma reatividade de $0,05 \%$ em 2005 e $0,11 \%$ em 2006 . Deve-se considerar ainda o fato de que, neste estudo, o índice de inaptidão foi calculado sobre o total de doadores/ano enquanto os dados disponíveis da hemorrede brasileira têm como base o total de doações.

Estudo de soro prevalência de HTLV em doadores de sangue de grandes áreas urbanas no Brasil, pelo ELISA, entre os anos de 1995 e 2000 , encontrou taxas que variaram de $0,04 \%$ em Florianópolis-SC e $1 \%$ em São Luis-MA, demonstrando maior prevalência nas cidades da região nordeste ${ }^{9}$.

Quanto aos doadores confirmados por WB, observamos em Uberaba, entre 1995 e 2008, soropositividade de 0,02\%. Considerando-se apenas o ano de 2008 essa ocorrência cai para 0,01\%. Em Belo Horizonte-MG, a prevalência em doadores de sangue, entre 1993 e 2004, foi de 0,05\% ${ }^{21}$. Estudo na Fundação Pró- sangue (SP), em que analisou 9.942 amostras na primeira quinzena de novembro de 2001 , registrou prevalência foi de $0,06 \%{ }^{22}$. Índice duas vezes maior que o observado no HRU naquele ano.

Outros estudos mostram prevalência de infecção pelo HTLV, através da técnica do WB, de 0,07\% em Maringá-PR (entre 2003 e 2006) $)^{23}, 0,11 \%$ em Rio Branco-AC (entre 1998 e 2001) $)^{24}$ e 0,3\% no interior da Bahia (década de 90) ${ }^{25}$, sendo a Bahia o estado com maiores índices de prevalência ${ }^{1,26}$.

Desigualdades no tamanho das amostras, diferenças de metodologia empregada, condições socioepidemiológicas e pluralidade de etnias nas populações estudadas, podem ser responsáveis pelas diferentes taxas encontradas nas diversas regiões do país ${ }^{1}$. Junte-se a isso, o fato de que muitos hemocentros do Brasil não realizam a testagem confirmatória (WB), não refletindo a real prevalência e dificultando a comparação entre as diferentes publicações?.

No Brasil, estima-se que a prevalência seja entre 20 e 100 vezes maior que nos Estados Unidos e Europa ${ }^{4}$. Numa pesquisa nos Estados Unidos da América, analisando 4,5 milhões de amostras, cerca de $0,016 \%$ se mostraram positivas pelo $\mathrm{WB}^{1}$. A infecção pelo vírus parece ser rara no continente Europeu, onde doadores de sangue em geral apresentem prevalência inferior a $0,001 \%^{27}$.

Nos 14 anos avaliados, neste estudo, observou-se uma moderada tendência decrescente $(\mathrm{r}=-0,5)$ de soro positividade pelo ELISA e confirmado pelo WB, com maior ocorrência no período de 1995 a 1998. Tanto para o teste ELISA quanto para o WB, houve uma redução significativa da sorologia positiva para HTLV, no período de 2002 a 2008 em comparação ao período anterior. Comportamento semelhante ao observado na Fundação Pró-Sangue (SP), onde a prevalência de HTLV em doadores foi de 0,17\% em 1996 e 0,06\% em $2001^{22}$.

Uma possível explicação para a queda de ocorrência em nossos achados e na maioria das publicações seria a exclusão permanente e gradativa de doadores repetidamente soroposivos e ao aprimoramento dos testes sorológicos, que vêm se mostrando mais específico. Ademais até mesmo o WB pode apresentar discordância de resultados quando comparados dois kits diferentes ${ }^{1,25}$.

A criação do Centro de Testagem e Aconselhamento (CTA) de Uberaba, em 1998, pode também ter contribuído para a redução da prevalência da soropositividade nos anos subsequentes. Com o CTA, indivíduos, sobretudo promíscuos sexuais, que doavam sangue para testagem sorológica, passavam a contar com um serviço específico para esse objetivo.

Observamos, nos 36 doadores infectados pelo HTLV (WB positivos), igual número de homens e mulheres. No entanto, é importante ressaltar que a maioria $(71,8 \%)$ dos nossos doadores, a semelhança dos demais Hemocentros brasileiros, é do gênero masculino. Assim, verificamos uma incidência maior no sexo feminino, estatisticamente significante. Uma possível explicação seria a maior chance de transmissão sexual homem-mulher. Trabalhos realizados mostram chances de transmissão de $60 \%$ de homem para mulher e menos de $1 \%$ de mulher para homem, em casais em que um dos parceiros é soropositivo ${ }^{1,4,28}$.

Encontramos, à semelhança de relatos da literatura, maior índice de infecção em idade igual ou superior a 30 anos; contudo, sem significância estatística. Tal fato poderia ser explicado pelo aumento progressivo no título de anticorpos com o tempo; efeito coorte, onde grupos mais velhos refletem a prevalência mais alta, devido ao maior tempo de exposição e/ou ter contraído a infecção no passado 
(visto que a infecção pelo HTLV-I estaria em declínio); soroconversão tardia (status soronegativo no início da infecção) e ainda, a fatores hormonais, já que um estudo no Japão mostrou maior transmissão do HTLV-1, no período pós-menopausa e em idade mais avançada ${ }^{1,28}$.

Em síntese, observamos que a incidência de HTLV-1/2 no HRU foi inferior aos relatos da literatura brasileira, caiu gradativamente ao longo dos 14 anos avaliados e foi predominante no gênero feminino. De modo geral, esses dados refletem o papel das triagens clínicoepidemiológicas e sorológica para melhoria da qualidade do sangue coletado e, consequentemente, aumento da segurança transfusional no Hemocentro Regional de Uberaba.

\section{AGRADECIMENTOS}

Agradecemos aos funcionários do Hemocentro Regional de Uberaba (HRU) e à Fundação Hemominas, pela contribuição no desenvolvimento desse estudo.

\section{CONFLITO DE INTERESSE}

Os autores declaram não haver nenhum tipo de conflito de interesse no desenvolvimento do estudo.

\section{SUPORTE FINANCEIRO}

Fundação de Amparo à Pesquisa do Estado de Minas Gerais (FAPEMIG).

\section{REFERÊNCIAS}

1. Soares BCC, Proietti FA, Proietti ABFC. Os vírus linfotrópicos de células T humanos (HTLV) na última década (1990-2000): Aspectos epidemiológicos. Rev Bras Epidemiol 2001; 4:81-95.

2. Martins ML, Stancioli EFB. Patogênese da infecção pelo HTLV. In: Proietti ABFC et al, editores. Cadernos Hemominas: HTLV-I HTLV-II. $4^{a}$ ed. Vol XIII. Belo Horizonte (MG): Fundação HEMOMINAS; 2006. p. 21-45.

3. Blattner WA, Gibbs WN, Saxinger C, Robert-Guroff M, Clark J, Lofters W, et al. Human T-cell leukaemia/lymphoma virus-associated lymphoreticular neoplasia in Jamaica. Lancet 1983; 8341:61-64.

4. Borducchi DMM, Kerbauy J, Oliveira JSR. Linfoma/Leucemia de células T do adulto. São Paulo. Rev Assoc Med Bras 1999; 45:63-70.

5. Castro-Costa CM, Salgueiro MR, Caron H. Tropical spastic paraparesis in Northeastern Brazil. Arq Neuropsiquiatr 1989; 47:134-138.

6. Gessain A, Barin F, Vermant JC, Gout O, Maurs L, Calender A, et al. Antibodies to human T-lymphotropic virus type I in patients with tropical spastic paraparesis. Lancet 1985 ; 8452:407-410.

7. Olivo RA, Martins FFM, Soares S, Moraes-Souza H. Adult T-cell leukemia/ lymphoma: report of two cases. (Leucemia/linfoma de células $\mathrm{T}$ do adulto: relato de dois casos). Rev Soc Bras Med Trop 2008; 41:288-292.

8. Proietti ABFC, Ribas JGR, Catalan-Soares BC, Martins ML, Melo GEAB, Martins-Filho OA, et al. Infecção e doença pelos vírus linfotrópicos humanos de célula T (HTLV-I/II) no Brasil. Rev Soc Bras Med Trop 2002; 35:499-508.

9. Soares BCC, Proietti ABFC, Proietti FA. Interdisciplinary HTLV Research Group Heterogeneous geographic distribution of human T-cell lymphotropic viruses I and II (HTLV-I/II): serological screening prevalence rates in blood donors from large urban areas in Brazil. Cad Saude Publica 2005; 21:926-931.

10. Tokudome S, Tokunaga O, Shimamoto Y, Miyamoto Y, Sumida I, Kikuchi M, et al. Incidence of adult T-cell leukemia/lymphoma among human T-lymphotropic virus type I carriers in Saga, Japan. Cancer Res 1989; 49:226-228.
11. Yoshida M, Seiki M, Yamaguchi K, Takatsuky K. Monoclonal integration of human T-cell leukemia provirus in all primary tumors of adult T-cell leukemia suggests causative role of human T-cell leukemia virus in this disease. Proc Natl Acad Sci US A 1984; 81:2534-2437.

12. Kalyanaraman VS, Sarngadharan MG, Rober-Guroff M, Miyoshi I, Golde D, Gallo RC. A new subtype of human T-cell leukemia virus (HTLV-II) associated with a T-cell variant of hairy cell leukemia. Science 1982; 218:571-573.

13. Manns A, Blattner WA. The epidemiology of the human T-cell lymphotropic virus type I and type II: etiologic role in human disease. Transfusion 1991; 31:67-75.

14. Kitagawa T, Taguchi H, Miyoshi T, Tadokoro M. Antibodies to HTLV-I in japanese imigrants in Brasil. J Am Med Assoc 1986; 256:2342.

15. Soares BCC, Proietti FA. HTLV-1 e 2: Aspectos Epidemiológicos. In: Proietti ABFC, et al, editores. Cadernos Hemominas: HTLV-I HTLV-II. $4^{a}$ ed. Vol XIII. Belo Horizonte (MG): Fundação Hemominas; 2006. p. 69-85.

16. Ministério da Saúde. Normas Técnicas para Coleta, Processamento e Transfusão sanguínea. 1a edição, 1994.

17. Carbolante EMSR, Penteado FCL, Medeiros L, Kashima S, Tkayanagui OM, Covas DT. Clonagem e expressão da glicoproteína transmembrana do vírus linfotrópico de células T humanas em sistema procarioto. Rev Soc Bras Med Trop 2007; 40:277-281.

18. Ministério da Saúde. HTLV-I/ II: Triagem e diagnóstico sorológico em unidades hemoterápicas e laboratórios de saúde pública Brasília; 1998. p. 15,23,40.

19. Jaques MC. Bioestatística - Princípios e Aplicações. $2^{\text {th }}$ ed. Editora Artmed; 2003.

20. Ministério da Saúde. Agência Nacional de Vigilância Sanitária - ANVISA; 2007. Disponível em: <www.anvisa.gov.br/sangue/índex.htm> Acessado em 2007.

21. Carneiro-Proietti AB, Namen-Lopes MS, Lobato MM, Drummond PC Lobato R. HTLV-1/2 in a Public Transfusion Center in Belo Horizonte, BrazilAspects of Hemovigilance: Transfusion Transmittable Infections. Vox Sang 2007; 93:45

22. Salles NA, Sabino EC, Barreto CB, Barreto AME, Otani MM, Chamone DF Descarte de bolsas de sangue e prevalência de doenças infecciosas em doadores de sangue da Fundação Pró-Sangue/Hemocentro de São Paulo. Rev Panam Salud Publica 2003; 13:111-116.

23. Veit APT, Mella EAC, Mella-Junior SE. Soroprevalência do vírus linfotrópico de células T humanas (HTLV-I/II) em indivíduos doadores de sangue do hemocentro da cidade de Maringá-PR. Arq Cienc Saude Unipar Umuarama 2006; 10:123-126.

24. Colin DD, Alcântara Junior LC, Santos FLN, Uchôa R, Tavares-Neto J. Prevalência da infecção pelo vírus linfotrópico humano de células $\mathrm{T}$ e fatores de risco associados à soropositividade em doadores de sangue da cidade de Rio Branco, AC, Brasil (1998-2001). Rev Soc Bras Med Trop 2003; 6:677-683.

25. Britto APCR, Galvão-Castro B, Straatmann A, Santos-Torres S, Tavares-Neto J. Infecção pelo HTLV-I/II no Estado da Bahia. Rev Soc Bras Med Trop 1998; 31:35-41.

26. Mota A, Nunes C, Melo A, Romeo M, Boasorte N, Dourado I, et al. A casecontrol study of HTLV-infection among blood donors in Salvador, Bahia, Brazil - associated risk factors and trend towards declining prevalence. Rev Bras Hematol e Hemot 2006; 28:120-126.

27. Taylor GP. The epidemiology of human T-cell leukaemia/lymphoma virus type I in Europe. J Acquir Immune Defic Syndr Hum Retrovirol $1996 ; 13: 8-14$.

28. Kajiyama W, Kashiwagi S, Ikematsu H, Hayashi J, Nomura H, Okochi K. Intrafamilial transmission of adult T-cell leukemia virus. J Infect Dis 1986; 154:851-857. 